\title{
AVALIAÇÃO DOS TEORES DE OXALATO EM FARINHA DE RESÍDUOS DE ACEROLA, GRAVIOLA E TANGERINA
}

\author{
M. M. A. SOUSA ${ }^{1}$, D. N. SENA ${ }^{1}$, M. M. B. ALMEIDA ${ }^{2}$, P. H. M. SOUSA ${ }^{3}$, R. W. \\ FIGUEREDO' ${ }^{1}$. \\ ${ }^{1}$ Universidade Federal do Ceará, Departamento de Tecnologia de Alimentos \\ ${ }^{2}$ Universidade Federal do Ceará, Departamento de Química Analítica e Físico-Química \\ ${ }^{3}$ Universidade Federal do Ceará, Instituto de Cultura e Arte \\ E-mail para contato: manuelaaguiar4@gmail.com
}

\begin{abstract}
RESUMO - Os resíduos provenientes do processamento de frutas compõem um material rico em componentes nutricionais que poderia ser utilizado na alimentação humana. Uma alternativa para o aproveitamento desses resíduos é a obtenção de farinha. No entanto, algumas dessas farinhas podem conter fatores antinutricionais, como os oxalatos, os quais afetam negativamente a biodisponibilidade de nutrientes requeridos pelo corpo. Assim, o presente trabalho avaliou os teores de oxalato em amostras de farinhas proveniente de resíduos do processamento de Acerola (Malpighia glabra), Graviola (Annona muricata) e Tangerina (Citrus reticulata). As amostras de resíduos (congeladas) do processamento das frutas investigadas foram desidratadas e trituradas para obtenção das farinhas. A determinação do oxalato total foi realizada por permanganimetria. As farinhas pesquisadas apresentaram valores de oxalato variando entre $12,55 \mathrm{mg} / 100 \mathrm{~g}$ (acerola) e 16,11 $\mathrm{mg} / 100 \mathrm{~g}$ (tangerina). Tais valores não causam alterações indesejáveis ao funcionamento do organismo humano, e portanto, não representam preocupação quanto à ingestão dos produtos investigados.
\end{abstract}

\section{INTRODUÇÃO}

O consumo mundial de frutas tem crescido nos últimos anos a uma taxa média anual de $5,6 \%$. Parte deste crescimento pode ser explicado pela mudança de hábito dos consumidores, os quais cada vez mais procuram nas frutas, a garantia de um alimento saudável e funcional. Segundo a Organização Mundial de Saúde (OMS), o consumo per capita recomendado por ano é de $146 \mathrm{~kg}$ de frutas. No Brasil, este consumo é de apenas $57 \mathrm{~kg}$. É neste cenário que surge o mercado das polpas de frutas, cujas vantagens vão desde a garantia de oferta dos sabores da fruta durante o ano inteiro, passando pela oportunidade de agregação de valor e pelo aproveitamento do excedente de produção das frutas (LEAL,2003). Além disso, a polpa é de 
fácil transporte e armazenamento e possui vida de prateleira de aproximadamente um ano, desde que conservada e exposta ao consumo de maneira adequada (MENDES,2008).

Com o crescente aumento de consumo de frutas e polpas, há o aumento da quantidade de resíduos sendo que quase $60 \%$ do peso total das frutas são descartados na forma de resíduos e jogados sem nenhum tratamento no meio ambiente, após passarem pelo processamento para obtenção de sucos, polpas e doces nas agroindústrias. Todo este material é uma fonte rica em vitaminas, minerais, energia, fibra e proteína, que pode ser utilizada em rações como alternativa para substituir os ingredientes tradicionais, na tentativa de reduzir os custos com alimentação animal. (LIMA,2010)

O ácido oxálico é formado nas plantas pela oxidação incompleta de carboidratos ocasionada pela ação de fungos (Aspergillus niger) ou bacterias (acetobacter). Nos animais, o acido oxalico é produzido pelo metabolismo de carboidratos, via ciclo do acido tricarboxilico (ROCHA, 2009).

O oxalato está presente na dieta humana, sendo encontrado em diversos vegetais,podendo ser resultado do metabolismo do aminioacido (glicina) ou do acido ascorbico. Ele afeta a saúde de duas mareiras distintas: após sua absorção pelo organismo, produz sais insoluveis de cálcio (presente na circulação) que podem precipitar nos rins contribuindo para formação de cálculo renal; e, antes da absorção, pela reação com o cálcio da dieta, diminuindo sua assimilação pelo organismo (PEREZ,2000). O cálculo renal ou nefrolitíase é uma doença multifatorial que se relaciona com desordens genéticas e fatores ambientais. Aproximadamente $80 \%$ dos cálculos renais contêm cálcio, pois este mineral reage facilmente com o oxalato, formando oxalato de cálcio (SANTOS, 2006).

Apesar de ser bastante citado as características do oxalato em pesquisas cientificas, ainda existem poucas pesquisas visando conhecer essa propriedade em alimentos no geral e especialmente em farinhas de frutas.

Portanto, devido a excassez de trabalhos com essa temática, faz-se necessario o conhecimento destes residuos para que sejam conhecidas as suas eventuais aplicabilidades tanto para enriquecimento de preparos para consumo humano ou para alimentação animal. Assim, o presente trabalho tem como objetivo avaliar a presença dessa substância em farinhas de residuos de três frutas: acerola, graviola e tangerina

\section{MATERIAL E MÉTODOS}

Os resíduos das frutas foram cedidos por uma indústria que realiza o beneficiamento de frutas para preparo de polpas de frutas. Esses foram acondicionados em sacos plásticos recolhidos e conduzidos ao Laboratório de Frutos e Hortaliças da Universidade Federal do Ceará, onde foram mantidos a temperatura de $-18^{\circ} \mathrm{C}$. Para o descongelamento, foram mantidos a temperatura de refrigeração $\left(4^{\circ} \mathrm{C}\right)$, para que não houvesse crescimento microbiano e posteriormente foram desidratados em estufa de circulação forçada de ar a $65^{\circ} \mathrm{C}$ por $60 \mathrm{~h}$. Após total desidratação, foram triturados com auxílio de processador e peneirados até atingir 
granulometria $1,0 \mathrm{~mm}$ a $1,4 \mathrm{~mm}$. Em seguida, foram acondicionados em recipientes envoltos com papel alumínio e recobertos com filme de PVC (policloreto de vinila) e conservados a temperatura ambiente.

Para a análise do teor de oxalato total pesou-se aproximadamente $0,150 \mathrm{~g}$ de cada amostra em um frasco erlenmeyer de $250 \mathrm{~mL}$, onde em seguida adicionou-se $50 \mathrm{~mL}$ de solução de $\mathrm{H}_{2} \mathrm{SO}_{4}$ 1:8. Esta mistura foi agitada a $60{ }^{\circ} \mathrm{C}$ por 1 hora para dissolver o sólido, foi filtrada e posteriormente foi quantificado o teor de oxalato total através da permanganimetria, usando $\mathrm{KMnO}_{4}$ 0,02 mol.L ${ }^{-1}$ (DAY e UNDERWOOD, 1986). As análises foram realizadas em triplicata

\section{RESULTADOS E DISCUSSÃO}

Os resultados encontrados estão apresentados no Gráfico 1. Conforme esse gráfico pôde-se verificar que as amostras em estudo não apresentaram valores de oxalato preocupantes, uma vez que estes variaram entre $12,55 \mathrm{mg} / 100 \mathrm{~g} \pm 1,96$ (acerola) e $16,11 \mathrm{mg} / 100 \mathrm{~g} \pm 0,21$ (tangerina), não atingindo valores suficientes para causar alterações na disponibilidade do cálcio no organismo.

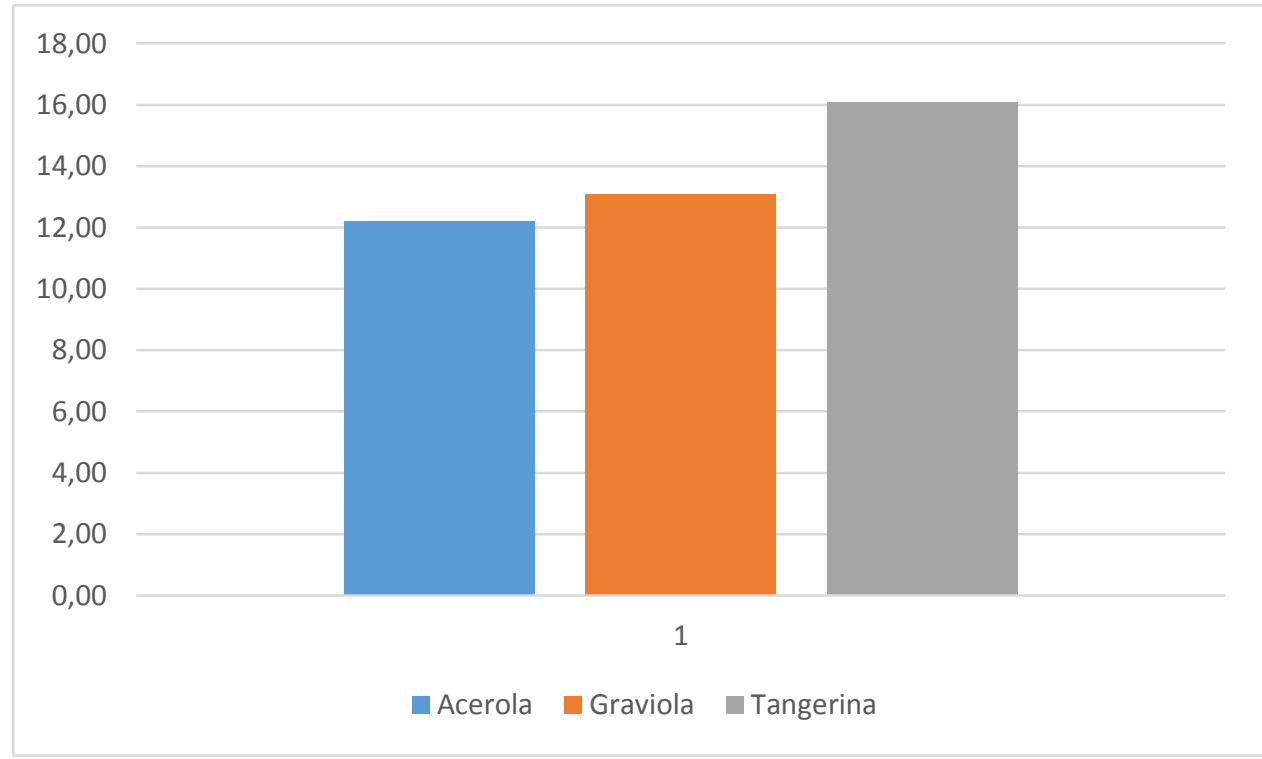

Figura 1 - Gráfico dos Teores de oxalato $(\mathrm{mg} / 100 \mathrm{~g})$ nas farinhas de resíduos do processamento de acerola, graviola e tangerina.

Acredita-se que os baixos teores de oxalato, são consequência dos cuidados durante o acondicionamento da matéria prima das farinhas. Sabe-se que a grande maioria dos fungos é incapaz de crescer na faixa de atividade de água (Aw) entre 0,61-0,70 (SILVA,2008) e os valores de atividade de água obtidos nas farinhas foram 0,41(acerola), 0,35(graviola), 0,51(tangerina) ou seja, são valores bem inferiores ao ideal para crescimento de qualquer 
microrganismo. Adicionalmente, é conhecido que o emprego da temperatura de $65^{\circ} \mathrm{C}$ por $60 \mathrm{~h}$ também é efetivo contra o crescimento de microrganismos.

Esses dados estão concordantes com os resultados obtidos por Lima (2008) em análise do teor de oxalato presente de espinafre consumido no Brasil (Tetragonia expansa) comumente chamado de espinafre da Nova Zelândia, o qual encontrou o valor de $10,85 \mathrm{mg} / 100 \mathrm{~g}$ de matéria seca.

$\mathrm{Na}$ pesquisa de Isaac e Ekpa (2009), ao investigarem os antinutricionais em duas variedades de peras africanas, encontraram-se valores de oxalato $(13,20$ e 17,60 mg/100g) semelhantes aos resultados encontrados nesse trabalho. Santos (2006) em estudo relacionando o efeito do cozimento sobre alguns fatores antinutricionais em folhas de brócolis, couve-flor e couve, encontrou valores maiores, visto que os teores médios encontrados para ácido oxálico em $100 \mathrm{~g}$ de matéria seca foram de 60,53 mg no brócolis, 49,66 mg na couve-flor e 38,09 mg na couve.

De forma geral, as frutas são ricas em ferro, porém a presença de outros compostos, como fibras alimentares, fitatos e oxalatos, pode tornar o ferro menos absorvível pelo intestino humano (OLIVEIRA, MARCHINI, 1998). Em contrapartida, sua absorção fica facilitada com níveis adequados de vitamina C (LIMA et al, 2008). Os resultados de vitamina $\mathrm{C}$ nas farinhas estudadas, obtidos por esse grupo de pesquisa, foram valores aceitáveis e bem superiores aos da IDR (60 mg/dia), uma vez que os valores encontrados fornecem de 139\% (graviola) a $205 \%$ (acerola) da IDR.

\section{CONCLUSÕES}

Conclui-se que os teores de oxalato encontrados em farinha proveniente de resíduos do processamento de acerola, graviola e tangerina não são suficientes para influenciar na disponibilidade do cálcio no organismo humano e causar alterações indesejadas no seu funcionamento.

\section{REFERÊNCIAS}

BRASIL. Portaria SVS/MS no 33, de 13 de janeiro de 1998. Tabelas de Ingestão Diária Recomendada (IDR). Diário Oficial da União, 16 jan. 1998.

DAY, R.A.; UNDERWOOD, A. L. Qualitative Analysis. New Delhi, India: Prentice Hall Publications. 1986, 701p.

ISAAC, I. O.; EKPA, O. D. MineraIs and Anti-Nutrients in Two Varieties of African Pear (Dacryodes edulis). J. Food Technol., n. 7, v. 4, p. 106-110, 2009 
LEAL, Romario C; Reis, Valéria B. dos; LUZ, Djavania A. AVALIAÇÃO DE PARÂMETROS FISICO-QUÍMICO DE POLPAS CONGELADAS DE GRAVIOLA COMERCIALIZADA EM SUPERMERCADOS DE SÃO LUÍS - MA. Cad. Pesq., São Luís, v. 20, n. 2, maio/ago. 2013

LIMA, G.P.P. et al. Parâmetros bioquímicos em partes descartadas de vegetais. PROGRAMA Alimente-se Bem: tabela de composição química das partes não convencionais dos alimentos. São Paulo: SESI, 2008.

LIMA, Misleni Ricarte de. Avaliação de resíduos de frutas nas rações de tilápia do Nilo.2010. Dissertação (Mestrado em Zootecnia) - Programa de Pós-Graduação em Zootecnia da Universidade Federal Rural de Pernambuco, PE,2008.

MENDES, P. A. M. Avaliação dos parâmetros físico-químicos determinados nos certificados oficiais de análise das polpas de frutas com padrões de identidade e qualidade. 2008. Dissertação (Mestrado em Ciências Agrárias) - Faculdade de Agranomia e Medicina Veterinária, Universidade de Brasília, Brasília, DF, 2008.

OLIVEIRA, J. E. D; MARCHINI, J. S. Ciências nutricionais. São Paulo: Sarvier, 1998. 403 p.

PEREZ, E.F. Desenvolvimento de um biosensor amperométrico para oxalato, UNICAMP, 2000

ROCHA, Regina Santos Rocha Procedimentos e Avaliação Quimica de Parametros de Interesse Nutricional de Espinafre Comercializado na Bahia, Dissertação (Mestrado em Ciencias Naturais-Quimica) - Universidade Federal da Bahia, Bahia. 2009.

SANTOS, M. A. T. Efeito do Cozimento sobre alguns Fatores Antinutricionais em folhas de Brócoli, Couve-Flor e Couve. Ciênc. Agrotec., v. 30, n. 2, p. 294-301, 2006.

SILVA, LEONARDO FILIPE DA. FUNGOS: um estudo sobre a sua ocorrência nos alimentos. (Dissertação-Especialista em Microbiologia). Departamento de Microbiologia do Instituto de Ciências Biológicas da Universidade Federal de Minas Gerais, 2008. 